\title{
Research and Analysis of Shanghai Agricultural Logistics
}

\author{
Hong Liu \\ Beijing Wuzi University, Beijing, China \\ Email: liuhong_cc66@yahoo.com
}

Received 24 June 2016; accepted 17 July 2016; published 20 July 2016

Copyright (C) 2016 by author and Scientific Research Publishing Inc.

This work is licensed under the Creative Commons Attribution International License (CC BY). http://creativecommons.org/licenses/by/4.0/

c) (i) Open Access

\begin{abstract}
Agricultural economy is a measure of a country or region. An important indicator of the agricultural development determines the development of the region, including agricultural farming, forestry, animal husbandry and fishery. Agriculture research influence of various factors on the agricultural economy of the present study has important basis. The main object of this study is to explore the factors that influence the development and direction of local agricultural logistics. Shanghai agricultural development study is the use of SPSS software analysis. Four main factors affect agriculture in Shanghai independent sample hypothesis testing. You can analyze the data which are obtained by the presence of significant differences between the samples. This paper puts forward the correlation analysis of agricultural economy; it presents the reliability of recommendations to develop agricultural logistics. The authors consider that we should be in control of agricultural development in Shanghai. We need to develop agriculture and aquatic products logistics, which is the primary task of development in Shanghai today.
\end{abstract}

\section{Keywords}

\section{Agricultural Economy, Agricultural Logistics, Shanghai}

\section{Introduction}

Agriculture is now the focus of many scholars studied, because agriculture is a measure of a region or a country important indicator of economic progress but also relies on the agricultural development of the logistics industry. The development of the logistics industry needs the help and support of local government. Thus, agricultural logistics and agricultural economy is linked to a whole, at all times and not be divided. Shanghai is a China's major city, and Shanghai is an important coastal areas. Seafood is the focus of the development of the object. The development of Shanghai directly affects China's economic development, in order to have a comprehensive un- 
derstanding of Shanghai. This article was from Shanghai agriculture departure, main degree of difference between the various parts of agriculture, agricultural output value and relevance of Shanghai, which made recommendations for the development of reliable Shanghai Agricultural logistics. Many scholars have on agricultural economic research division commander and two scholars Chen (2013) to the northeast of agriculture as the foundation, from the perspective of protecting the ecological environment of the proposed development of agriculture [1]. Hucui Hua and Liu Shoujiang (2010) from Nanchong City, Ho Ka fellow wood, for example, the use of AHP, draw the main factors of ecological agriculture and tourism development approach [2]. Zhaopei Hua (2013) using the gray correlation analysis method, derived factors in Henan Province and the rapid development of low-carbon low-carbon agriculture agriculture [3]. Weibai Gang and Han Jie from Beijing perspective, using Cobb-Douglas mathematical statistics, derived resources, economy and technology was the key factor in agricultural development [4]. After my investigation, research on Shanghai’s agricultural economy and agricultural logistics development is scarce and not very clear articles and methods, thus it is very important to research agricultural economy and agricultural development logistics.

\section{Shanghai Agriculture Analysis}

Under normal circumstances, the agricultural sector can be divided into four parts, farming, forestry, animal husbandry and fishery, intrinsically linked and differences between these four parts, in order to explore the relationship between the agricultural sector in Shanghai, we gather the Shanghai agriculture statistics from 2000 to 2014, to take a significant difference on SPSS software in Shanghai from 2000 to 2014, the agricultural index between samples T-test, analysis software, whether independent existence observed between samples having mutual correlation between the presence, or the sample. Shanghai from 2000 to 2014, agricultural value index as shown in Table 1.

Firstly, using SPSS analysis of the data in Table 1 will be paired samples T-test, the results from the data show, see if there is a significant difference between the two samples of agricultural data, this data is arranged in such a combination between the two samples combinations of two, respectively, the software can be drawn into six groups of data, the results shown in Table 2 .

\section{Table 1. Index of Shanghai agricultural statistics (Unit: 100 million).}

\begin{tabular}{cccccc}
\hline year & Crop farming & Forestry & Animal Husbandry & Fisheries & Agricultural output \\
\hline 2000 & 89.81 & 1.41 & 87.35 & 37.92 & 216.50 \\
2001 & 95.53 & 3.52 & 88.43 & 40.13 & 227.61 \\
2002 & 97.21 & 7.75 & 83.48 & 45.13 & 233.57 \\
2003 & 98.17 & 13.05 & 81.13 & 49.21 & 247.29 \\
2004 & 109.32 & 13.14 & 70.77 & 49.9 & 248.89 \\
2005 & 111.25 & 11.11 & 54.34 & 51.64 & 233.39 \\
2006 & 119.99 & 10.43 & 46.29 & 55.25 & 237.01 \\
2007 & 126.74 & 10.05 & 58 & 54.19 & 255.98 \\
2008 & 137.52 & 9.12 & 68.4 & 57.11 & 280.35 \\
2009 & 147.53 & 8.99 & 64.61 & 53.53 & 283.15 \\
2010 & 155.27 & 7.53 & 62.9 & 52.62 & 287.03 \\
2011 & 165.07 & 7.62 & 77.44 & 54.72 & 314.58 \\
2012 & 171.48 & 9.55 & 72.59 & 57.45 & 321.73 \\
2013 & 172.28 & 9.65 & 69.97 & 59.89 & 323.48 \\
2014 & 169.51 & 8.78 & 69.93 & 62.5 & 322.22 \\
\hline
\end{tabular}


From Table 2, we can conclude that the null hypothesis is paired test no significant difference between the two data samples, analysis of this data, because the value of sig are 0 , the conclusion should reject the original hypothesis, each sample there are significant differences between, indicating there is a big difference between Shanghai farming, forestry, animal husbandry and fisheries, the four that are specially designed to meet the law of development of the region, economic development indicators of each region are almost there is no correlation between the development of various indicators are independent, therefore, we concluded that this data is reliable.

In order to analyze an important indicator of economic development in Shanghai to promote agriculture, we need to Planting, between forestry, animal husbandry and fishery and agricultural output value of the four Shanghai correlation analysis, correlation analysis of modern mathematical analysis important application of technology, which can analyze the factors that promote agricultural development in Shanghai came out, it was concluded that the analysis of data, we can clearly see the correlation between the size of it for the study of economic development in Shanghai agriculture plays an important role. Using SPSS software to analyze the data in Table 1 correlation analysis, the conclusion as shown in Table 3.

We can clearly see from the data, the total agricultural output value of Shanghai and local farming are highest degree of correlation, the correlation coefficient was 0.970 , indicating that the value of agricultural crops grown mainly from Shanghai, the local government should see to local crops economic importance, vigorously send a crop planting and nurturing. In second place is the fishing, the correlation coefficient is 0.809 , the data show that the local agricultural economy to a certain extent on the need to support fisheries, local farmers should strengthen the development of fisheries in the original basis, to enhance learning in aquatic farming, for agricultural development in Shanghai to provide protection. Forestry and animal husbandry contribution to agricultural development in Shanghai to make low correlation coefficients were 0.198 and -0.107 , the correlation coefficient is 0.3 or less explain the low degree of correlation of the data samples and GDP, the negative description of the two indicators negative correlation between Shanghai's total agricultural output value of forestry to local small contribution to the development of forestry in local economic impact is not likely contribution of forestry and the contribution of farming have in common, animal husbandry and Shanghai economic development showed the opposite relationship, because with the development of animal husbandry, cattle and goat farming in Shanghai requires a lot of feed supply, animal husbandry needs to consume resources, agricultural resources of this phenomenon would lead to decreased agricultural output decreases, these gave the Shanghai authorities to provide the basis for research.

After analysis of software, from Table 4 and Table 5, the following conclusions can be drawn, Shanghai linear regression equation $\mathrm{y}=0.0326 \mathrm{X}_{1}+1.339 \mathrm{X}_{2}+1.018 \mathrm{X}_{3}+1.097 \mathrm{X}_{4}-15.781$, a total of about 2 by linear test, the data value DW meet the requirements, from Figure 1 and Figure 2 can be concluded that the residual agricultural factors are normally distributed, from the figure we can clearly see that is normally distributed, and all data were fit linear and fluctuation is near, the fit is good, can be used as evaluation of test results.

Table 2. Agriculture index paired difference test.

\begin{tabular}{cccccccccc}
\hline No & Mean & \multicolumn{2}{c}{ Deviation Standard } & Limit Lower & Error & $\mathrm{t}$ & $\mathrm{df}$ & Sig \\
\hline 1 & 122.33200 & 30.18061 & 7.79260 & 105.61853 & 139.04547 & 15.698 & 14 & 0.000 \\
2 & 60.73667 & 35.96646 & 9.28650 & 40.81911 & 80.65423 & 6.540 & 14 & 0.000 \\
3 & 79.03267 & 25.09833 & 6.48036 & 65.13367 & 92.93166 & 12.196 & 14 & 0.000 \\
4 & -61.59533 & 13.96671 & 3.60619 & -69.32984 & -53.86083 & -17.080 & 14 & 0.000 \\
5 & -43.29933 & 5.66584 & 1.46291 & -46.43697 & -40.16170 & -29.598 & 14 & 0.000 \\
6 & 18.29600 & 16.98834 & 4.38637 & 8.88817 & 27.70383 & 4.171 & 14 & 0.001 \\
\hline
\end{tabular}

Table 3. Factors relational data.

\begin{tabular}{cccccc}
\hline Factor Correlation & Agricultural output & Crop Farming & Forestry & Animal Husbandry & Fisheries \\
\hline Agricultural output & 1 & 0.970 & 0.198 & -.107 & 0.809 \\
\hline
\end{tabular}


Table 4. Collinearity diagnostics.

\begin{tabular}{ccccccc}
\hline Model & \multicolumn{3}{c}{ R F df1df2Sig } & Durbin-Watson \\
\hline 1 & 1.000 & 5026.612 & 4 & 10 & 0.000 & 2.268 \\
\hline
\end{tabular}

Table 5. Regression data.

\begin{tabular}{|c|c|c|c|c|c|}
\hline Model & B & Deviation Trial & version & $\mathrm{t}$ & Sig. \\
\hline constant & -15.781 & 5.233 & & -3.015 & 0.013 \\
\hline Crop Farming & 1.099 & 0.024 & 0.880 & 45.915 & 0.000 \\
\hline Forestry & 1.339 & 0.146 & 0.109 & 9.165 & 0.000 \\
\hline Animal Husbandry & 1.018 & 0.031 & 0.322 & 33.089 & 0.000 \\
\hline Fisheries & 1.097 & 0.136 & 0.196 & 8.045 & 0.000 \\
\hline
\end{tabular}

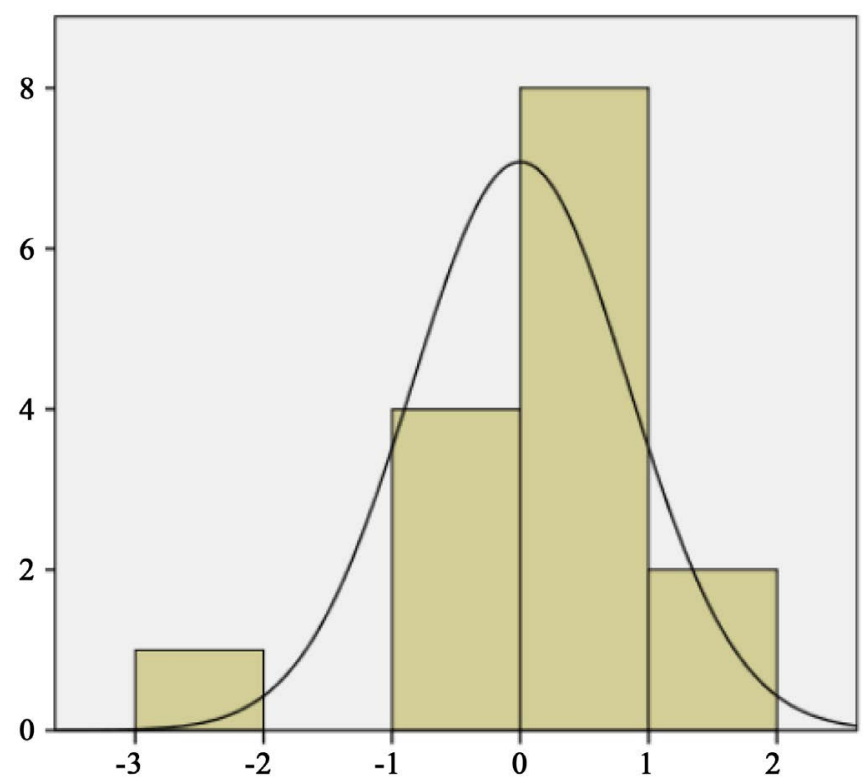

Figure 1. Normal distribution. $\mathrm{X}$ axis representative of regression standardized residual test, $\mathrm{Y}$ axis represent the data appears' frequency.

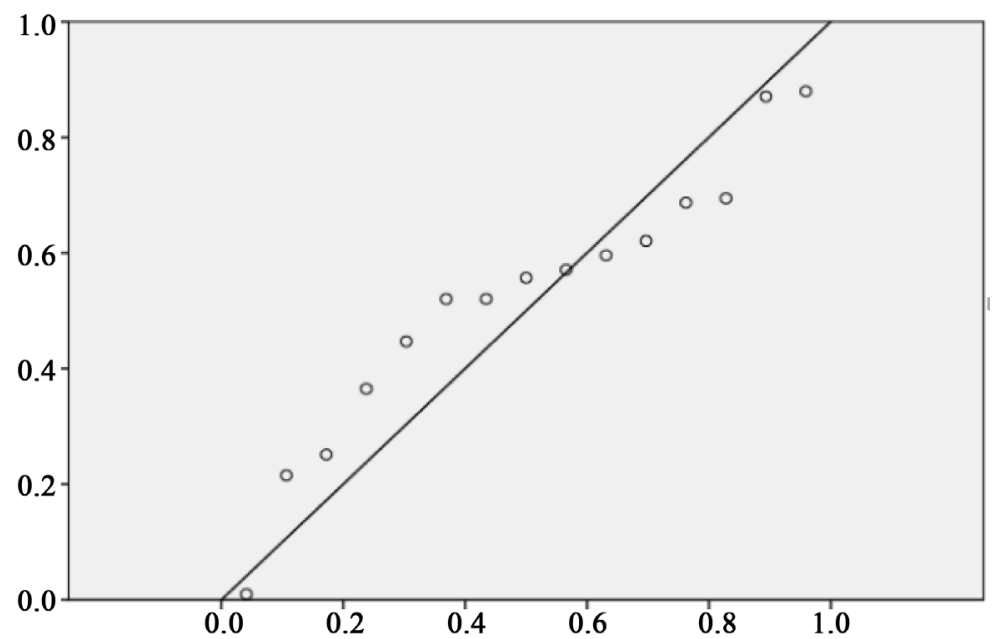

Figure 2. Goodness of fit. 


\section{Conclusion}

Development of agricultural enterprises and agricultural logistics in Shanghai is supposed to do now. Shanghai is a mainly agricultural planting. Planting good or bad depends on many aspects. Objects first planting need is for farmers, is the basis of farmers farming. The local government should strengthen incentives for farmers. Farmers' welfare increase will have a high interest in the production; so as to promote economic development has provided a guarantee. Secondly, local authorities regularly conduct training for farmers, so farmers planted theoretical knowledge of science, advanced cultivation techniques to teach farmers. The government should increase investment in rural households, the introduction of advanced cultivation equipment, and the introduction of well-known experts to explain to local farmers. The most important is to strengthen the development of local agricultural logistics. After food production, food circulation is bound to go through the logistics; the logistics process agricultural products, should be strengthened to ensure the quality of agricultural products, to ensure that the logistics chain without error, when necessary, can provide cold chain logistics of agricultural products to protect the temperature control in the logistics distribution process. Supervision and feedback mechanisms of local government should also pay attention to the factors that oversight mechanisms are present in the circulation of agricultural problems in the process. It can be advanced networking technology, the use of sensors to communicate information to the recipient, the recipient information to the leadership who will be timely feedback of information, to solve the problem to make the right decisions in a short time. Maintain fisheries development, emphasis on seafood logistics Shanghai also another important factor to consider. Shanghai is an important coastal city, is an important feature of the coastal city fishery developed, real-life people. They liked to eat seafood, which has become the people's consumption habits. Thus, in the original basis to develop fisheries, it can bring more profits for the Shanghai economy. The process of development, should focus on control technology, on the basis of maintaining the original development of fisheries, on fish, raise technical knowledge shrimp farmers were appropriate training. Good technical level is the protection of aquatic products breeding high standards, high levels of quality aquatic products breeding will increase, which makes the local aquatic great reputation, increase sales, increase profits. The development of fisheries in the process, should improve aquatic products logistics. Fish need to have a low temperature, poor activity. The environment and good, logistics transport, cold chain technology is an important part; it can ensure that fish can survive long-term. The phenomenon of death does not occur. The sensor is mounted in the transport car at any time may be an important indicator of aquatic environment, turbidity, oxygen content, etc. to convey to the manager. If there are problems, take the appropriate action immediately to alter aquatic environment. Quality seafood is the focus of people's concerns; the various departments should strengthen supervision and quality control of aquatic products in the supply chain process, strict control on the quality of aquatic products, aquatic products and timely organizational problems into consumption.

\section{References}

[1] Chen, S.S. (2013) Factors Affecting Carbon Farming Division Commander, Northeastern Provinces Develop Business Research. Business Research, 5, 159-165.

[2] Hua, Z.P. (2010) Based on Low-Carbon Agriculture Factors in Henan Province Gray Correlation Analysis. Henan Agricultural Sciences, 8, 167-170.

[3] Hu, C.H., Jiang, L.S. and Xu, W.C. (2013) Based on AHP Community Participation Ecological Agriculture Quantitative Evaluation Factors-A Wooden Nanchong Fellow Ho Ka Example. Mianyang Normal University, 5, 88-91.

[4] Gang, W.B. and Han, J. (2012) Urban Agriculture Cycle Influencing Factors-Taking Beijing as an Example. China Agricultural Resources and Regional Planning, 1, 31-39. 


\section{Submit or recommend next manuscript to SCIRP and we will provide best service for you:}

Accepting pre-submission inquiries through Email, Facebook, LinkedIn, Twitter, etc.

A wide selection of journals (inclusive of 9 subjects, more than 200 journals)

Providing 24-hour high-quality service

User-friendly online submission system

Fair and swift peer-review system

Efficient typesetting and proofreading procedure

Display of the result of downloads and visits, as well as the number of cited articles

Maximum dissemination of your research work

Submit your manuscript at: http://papersubmission.scirp.org/ 